\title{
GIS-analysis of ground transport accessibility of fire stations at regional scale
}

\author{
Ekaterina Podolskaia $^{\text {a, }}$, Dmitriy Ershov ${ }^{\text {a }}$, Konstantin Kovganko ${ }^{\text {a }}$ \\ ${ }^{a}$ Center of Forest Ecology and Productivity, Russian Academy of Sciences (CFEP RAS), ekaterina.podolskaia@ gmail.com \\ * Corresponding author
}

Keywords: Fire station, forest fire, ground transport accessibility, road network, GIS-analysis

\begin{abstract}
:
Geospatial approaches are widely used to organize access and to manage the extinguishing of forest fires globally. Term "transport accessibility" is used in a variety of geographical and economic researches. Assessment of transport accessibility is directly related to the feasibility study to locate the fire stations in a particular region. Location analysis of objects relative to other objects, while taking into account various quantitative and qualitative parameters, is a classical problem solved by geoinformation systems.
\end{abstract}

Present research work is aimed to be used to improve the situation with forest fires in Russia where one of the main asset of operational regional firefighting in the forests is a fire-and-chemical (fire) station. Traditionally station placement is under the responsibility of Russian region to which stations are administratively subordinate. The location of fire station is determined taking into account the species structure of forests, natural fire danger, road infrastructure and some other factors. Irkutsk region, one of the territories with the constant perennial fire danger in the forests, was chosen as a test area.

Using this area as a typical example of regional extent, an analysis of fire stations placement then planning the ground movement of fire brigades from a station to the forest fire locations has been carried out. Previously obtained results to create the shortest routes within three-hour accessibility for the fire hazardous seasons 2002-2017 are used. Russian regulatory documents of the forest industry are applied. Thus, topic of GIS analysis serves as a continuation of the study (http://cepl.rssi.ru/wp-content/uploads/2018/11/Podolskaya-E.S.-et.-al..pdf, in Russian) and various aspects of transportation problem are considered on the example of Irkutsk region.

We used the following input data: point layer of fire stations, road network (including roads of different classes and forest glades), and archive of forest fires detected using the spectroradiometer MODIS from the Aqua and Terra spacecraft. Additional data were collected from the open regional Internet sources. GIS analysis used ArcGIS ArcMap Desktop extensions such as Network Analyst, Spatial Analyst, and ArcGIS tools like ET GeoWizards (https://www.ian-ko.com/).

We have developed and have used a forest fire transport model of ground access by trucks for the Irkutsk region with the spatial arrangement of fire stations, two protection zones and road network. Speed of the forest fire trucks is classified into 5 groups, taking into account the official permissions and road class. Also every segment of road has its attributive data of speed "adjusted" by the elevation value of the ETopo2, an open-access model (https://www.ngdc.noaa.gov/mgg/global/etopo2.html). Taking into consideration these relief data allows to decrease the vehicle's speed in the mountainous conditions.

Based on the regional specifics and available data for a fire hazardous season, the following set of evaluation parameters was proposed, namely:

- $\quad$ Road network: roads existence, length, density, and configuration;

- $\quad$ Spatial distribution of detected forest fires;

- $\quad$ Territory of fire stations servicing.

All the listed parameters are interconnected to each other and, in combination, jointly impact the stations ground transport accessibility assessment at the regional level. We have used GIS-analysis methods such as buffering, allocation, and density, as well as geographic and directional distribution. Time frame of analysis is the full fire hazardous season.

Undertaken analysis for the forest fires detected within the ground protection zone (archive of 2002-2017) has shown that the fire stations' distribution was appropriate. The analysis was based on the assumption that stations had the same weight, geographical and transport location of the stations was reviewed in conjunction to the thematical forestry recommendations. To go further in the GIS analysis some characteristics (work force and technical resources) of the weighted stations could be added.

Additional factors of influence can be the location of protected areas with their specific access regime, seasonality of road use, forest fire zoning, forestry boundaries, economic criteria, placement of fire stations in the populated area, etc. It is 
advisable to conduct a fire stations placement analysis as a preparation event before and after the end of the fire-hazardous season to summarize the effectiveness of actions to extinguish forest fires in the region. Practical results of the study can be used as well to prepare the regional forestry development programs and plans.

The study was carried out as part of CFEP's theme "Methodical approaches to assess the structural organization and functioning of forest ecosystems", state registration number is AAAA-A18-118052400130-7. 